ISSN: 2224-0616

OPEN 2 ACCESS

Int. J. Agril. Res. Innov. Tech. 10(2): 100-109, December 2020 Available online at https://ijarit.webs.com DOI: https://doi.org/10.3329/ijarit.v10i2.51583

https://www.banglajol.info/index.php/IJARIT

\title{
Factors influencing adoption of high tunnels for tomato production in northeast district, Botswana
}

\author{
Dandy Badimo \\ Received 12 August 2020, Revised 13 December 2020, Accepted 24 December 2020, Published online 31 December 2020
}

\begin{abstract}
A B S T R A C T
The study was carried out to investigate constraints and determinants of high tunnels adoption for tomato production in the North-East District of Botswana, using household survey data sourced directly from 116 horticultural farmers during the months of May and June 2017. Descriptive statistics and a binary probit regression model were employed to analyze constraints and determinants of high tunnels adoption for tomato production. The prohibitive cost of high tunnels, inadequate knowledge on high tunnels, inadequate capital and markets were identified as major constraints that hinder high tunnels adoption. The adoption of high tunnels was found to be positively influenced by years of education, access to extension services and farm size. The findings suggest that encouraging tunnel designers to consider constructing the structure using local materials could be ideal to cut down on the startup cost. Strengthening extension service and re-engineering of the current extension system is necessary to improve the adoption rate of the technology.
\end{abstract}

Keywords: Botswana, High tunnels technology, Probit model, Tomato.

Okavango Research Institute, University of Botswana, Maun, Botswana. Private Bag 285 Maun, Botswana

*Corresponding author's email: dbadimo@gmail.com (Dandy Badimo)

Cite this article as: Badimo, D. 2020. Factors influencing adoption of high tunnels for tomato production in northeast district, Botswana. Int. J. Agril. Res. Innov. Tech. 10(2): 100-109. https://doi.org/10.3329/ijarit.v10i2.51583

\section{Introduction}

High tunnels are plastic-covered, passive solar heated houses used to modify the growing environment (Wells and Loy, 1993; Carey et al., 2009; O'Connell et al., 2012). There are various types of high tunnels depending on the frame structure, material of the frame and the covering material. The benefits associated with high tunnels include opportunities for season extension, improved yield, and quality, crop risk reduction (weather and diseases related risk) and intensive production capabilities on the limited land area (Waterer, 2003; O'Connell et al., 2012; Drost and Wytsalucy 2014). High tunnel technology has proved to be a viable alternative to open-field tomato production.

Tomato (Lycopersicon esculentum Mill.) is one of the main economic crops in the world. It is a versatile fruit consumed in diverse ways including raw (salads), as an ingredient in many dishes and sauces, making it the most consumed fruit in the world. In Africa, for instance, in 2013, the tomato was the most produced vegetable at 19.1 Metric Tonnes (MT) (FAO, 2013). In
Botswana, tomato demand is estimated at 12000 tonnes per month, however, local productivity range from $60-100$ tons per hectare depending on the variety and related production conditions (Disele, 2018), and this does not satisfy local demand. Currently, local production only affords to meet approximately $40 \%$ of horticultural produce demand (LEA, 2015).

The sluggish growth and unsustainable commercial production of tomatoes result from the shortness of the growing season and erratic weather conditions in Botswana (Baliyan, 2014). The situation is further exacerbated by climate change (World Economic Forum, 2016; Field et al., 2014); henceforth production in an open field has become a challenge. Tomato is a warmseason crop and cannot stand severe frost. For that reason, in Botswana, the open field tomato production period runs from October to March. However, the upward demands for year-round tomatoes have created a huge deficit. This has compelled the country to import substantial amounts of tomatoes, specifically from South 
Africa, to meet the country's demand (DAFF, 2017). Botswana's unfavourable climatic conditions have prompted exploring other farming systems for tomato production to keep up with the increasing demand. As a result, high tunnels were introduced around 2005 in Botswana. Subsequently, the government of Botswana, in support of the technology, established a protected farming (greenhouse, high tunnel, net shade) incubator for tomato production in Glenn Valley in 2011 providing training as a way to facilitate the rollout of the technology (LEA, 2015).

Despite the benefits associated with high tunnels and the establishment of a protected farming incubator for tomato production by the government seven years ago, there is still low adoption of the technology. This has resulted in the stagnation of tomato value chain development and bloated import bill of fresh tomatoes and associated products. The import bill for fresh tomatoes in 2014 and 2015 was BWP 32, 882,917.00 and BWP 33, 851,680.00 (1BWP $=0.097 \mathrm{U} \$ \mathrm{D}$ ), respectively (Statistics Botswana, 2016a). These drain the foreign exchange earnings and reverse government efforts to diversify the agricultural sector. Furthermore, high dependence on imports also makes the industry susceptible to international shocks.

Previous studies carried out in Botswana have mostly focused on horticulture productivity of open-field production systems and experimental studies of protected farming performance at research centres and schools (Baliyan, 2014; Baliyan and Rao, 2013; Madisa, 2012). The studies paid less attention to the awareness and adoption of the technologies at the farm level. Therefore, there was a need for novel research to investigate why there is low adoption of the high tunnels technology in North East District, Botswana. The overall objective of the study was to contribute to the understanding of the adoption process of the high tunnels technology for tomato production to inform future actions and promotional strategies. The study findings will aid the refocusing of associated policy thrust and research. The main aim of the study is consistent with key development strategies for achieving food security and promoting sustainable agriculture. Besides, the findings will assist in bridging the information gap associated with high tunnels adoption in the North East District with potential spillover to other districts.

\section{Theoretical and conceptual framework}

Since the classic work of Rogers (1962), there have been progressive efforts to explain innovations diffusion and technology adoption. Two commonly reiterated paradigms in literature are innovation diffusion and economic constraints paradigms (Ibrahim et al., 2012; Ramaeker et al., 2013; Kassa et al., 2014). The innovation diffusion model, following from the work of Rogers, holds that access to information about the innovation is the key factor determining the adoption decision. Nonetheless, the paradigm has previously been criticized as being "top-down" in orientation and thus lacking consideration for farm variables in its packaging (Roling, 1988). On the other hand, the economic constraint paradigm hypothesizes that asymmetrical distribution pattern of resource endowments are the major determinants of observed adoption behaviour (Aikens et al., 1975). The strength of the economic paradigm is the recognition of the importance of profitability and economic constraints to explain adoption behaviour, but it fails to recognize less tangible factors such as personal motivation or peer pressure (Prager and Posthumus, 2010).

Another paradigm gaining attention is the 'adopter perception' paradigm in agricultural economics (Apata, 2011; Murage et al., 2015). This paradigm argues that the perceived attributes of innovations influence adoption behaviour. Perception is determined by personal factors as well as physical factors of the land and institutional factors (Aubert et al., 2013. This study blended the three paradigms to reduce biasness in explaining the adoption decision of high tunnels.

Particular to the current study, the framework hypothesized relationships among variables assumed to influence the adoption of the high tunnels technology based on the theoretical and empirical review of relevant literature. Several factors have been found to influence the adoption of new technologies. These factors have been classified general into four broad categories namely; socio-economic, institutional, environmental and farmers perception on agricultural technology (Howley and Heanue, 2012; Ibrahim et al., 2012; D’Antoni et al., 2012; Aubert et al., 2013; Kassa et al., 2014). Specific factors that consistently surface from various literatures as key determinates include demographic factors such as gender, education, age, experience, and marriage status (Aubert et al., 2013; Labaran, 2015). Other factors are land size, wealth or asset accumulation, in-farm, and on-farm income, access to extension services, input and output market access, credit facilities, land tenure system as well as information and communication infrastructure (Al-Shadiadeh et al., 2012; Kassa et al., 2014; Manda et al., 2016). Nevertheless, this study was limited to farm size, head of household education, age, gender, occupation, farmer's experience, access to extension, access to credit, and distance to the market. 


\section{Materials and Methods}

\section{Study area}

North East District is the second smallest district in the country but the second principal horticultural district in Botswana (Fig. 1). The district lies between 27'15 and 28 East (longitude) and 20'30 and 21'25 South (latitude) (North-East District Development Plan 6, 2004). It covers a total area of $5120 \mathrm{~km}^{2}$, with a population of 167 500 (Central Statistics Office, 2011). Agriculture is the predominant economic activity in the district, with a large number of households participating in horticulture, pastoral farming and/or rain-fed arable farming. Other economic activities include transport and communication, finance, public administration, and manufacturing.

The minimum and maximum temperatures in the district are $5^{\circ} \mathrm{C}$ and $23^{\circ} \mathrm{C}$ in winter, and $17^{\circ} \mathrm{C}$ and $30^{\circ} \mathrm{C}$ in summer (Department of Meteorological Services, 2017). Annual average rainfall in the district ranges between $400 \mathrm{~mm}$ (in the south) and $500 \mathrm{~mm}$ (in the north) and the raining period is around October to March (North-East District Development Plan 6, 2004).

The district is mainly characterized by well drained to moderately deep silty sands and sandy clays (Ranganai et al., 2015). The district is regarded as a principal horticultural area in Botswana because of its positioning as it lies between two rivers, Shashe and Ramokgwebana, which are the main sources of water for horticultural production and the majority of the farms in the district are located adjacent to these rivers. North East District is second after Central District (Tuli to be specific) in tomato production (Statistics Botswana, 2016b). As of 2011, the district had a total of 271 horticultural farmers (Central Statistics Office, 2011).
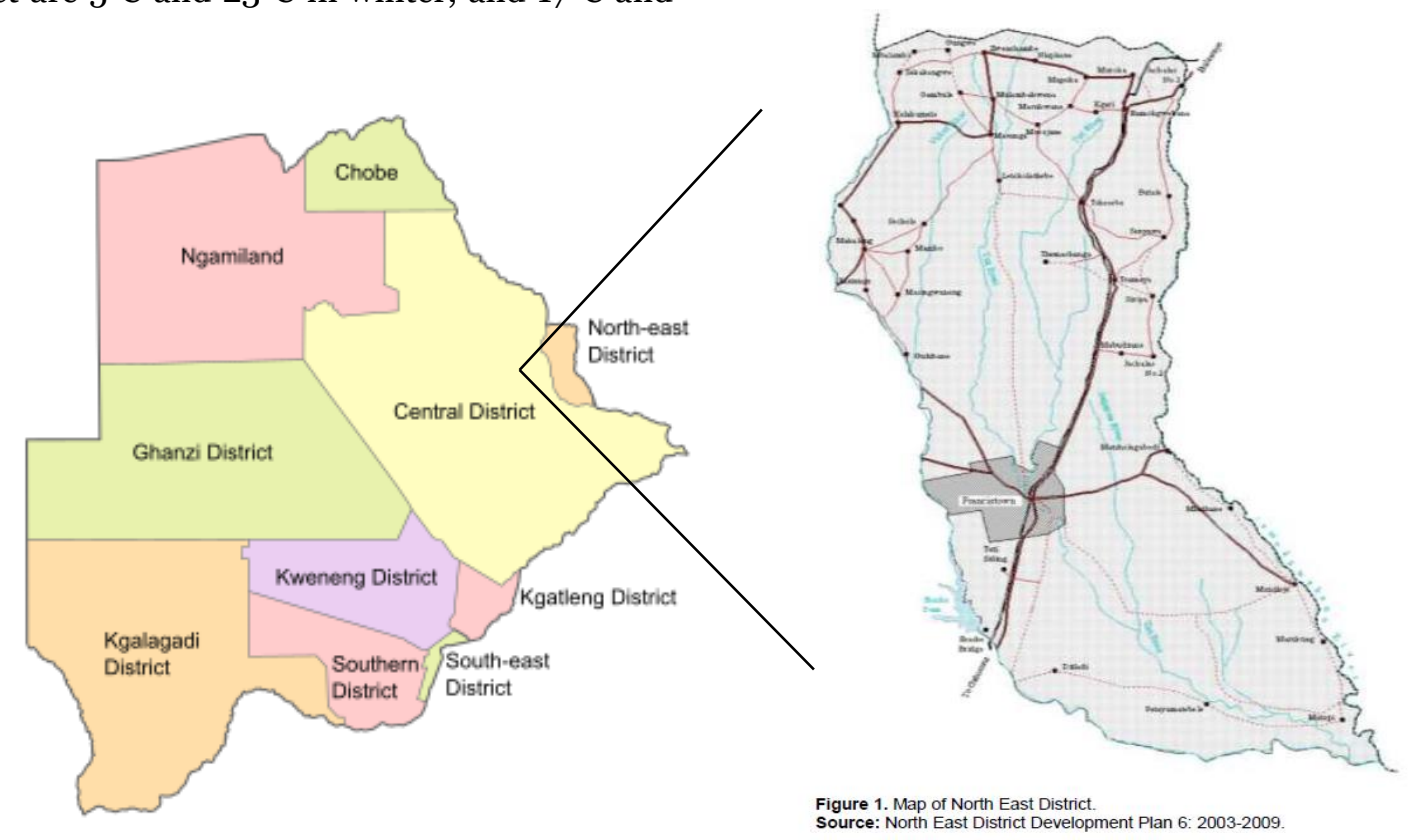

Fig.1. Map showing the location of the North East District in Botswana.

Source: North East District Development Plan

\section{Data and sampling procedures}

The study was a cross-sectional survey, which implied that data was collected at one point in time. The data was collected from $2^{\text {nd }}$ May to $5^{\text {th }}$ June 2017. Two data collection methods were employed, namely key informants interviews (KIIs) and household surveys (HHS). The household survey entailed administering a pretested questionnaire to sampled horticultural farmers in the district with the help of trained enumerators. The questionnaire was sub-divided into two sections; section A mainly focused on general demographic characteristics of the respondents. Section B covered questions related to high tunnels adoption and associated factors that influence its adoption. The questionnaire included both open and closed-ended questions to avoid restricting the participants' answers. For the key informants' interviews, Agribusiness officers in the district, Local Enterprise Authority (LEA, Glenn Valley), and National Agricultural Processing (NAPRO) officers were purposively chosen to have an in-depth discussion on issues important to the study for triangulation purpose. A list of questions was prepared focusing mainly on extension services and information dissemination strategies concerning high tunnels technology, to assist in obtaining necessary data from the officers. 
A stratified random sampling technique was employed to select participants for the study. Horticultural farmers in the district were segregated into two strata, non-tunnels adopters and tunnels adopters. Guided by the United Nations' (2005) handbook for designing household survey samples, a total of 85 nonadopters were randomly sampled and for high tunnels adopters, a census of 31 farmers was carried out due to their small number (Only $26.7 \%$ of the farmers had adopted the high tunnels as of 2017). Overall, 116 farmers participated in the survey.

\section{Analytical framework and empirical model specification}

Descriptive statistics, Chi-square analysis, t-test, and regression analysis were suitable to analyze the quantitative data collected from the survey. Qualitative analysis was imperative in addressing the open-ended questionnaire, especially from key informants' interviews. Statistical Package for Social Science (SPSS) version 21 and Stata were used for analysis.

\section{Empirical model specification}

A probit model was employed to identify factors influencing the adoption of high tunnels technology. Besides the probit model another commonly used dichotomous model for technology adoption is a logit model. The logit model is highly preferred when dealing with a large sample size because of its flexibility (Hosmer and Lemeshow, 2000). However, the two models are equally appropriate in analyzing cross-sectional data with a binary dependent variable and usually give identical results and a significant difference between the two models is attached to their tails (Gujarati, 2004). Therefore, based on literature, sample size, nature of the data and trial results from the two models, the probit model was chosen. There were two alternatives, the farmer has either adopted or not adopted the high tunnel technology. An individual $i$ decide to adopt a high tunnel if the perceived net benefit associated with adoption choice is higher than the net benefit associated with the decision not to adopt. The perceived net benefit by individual $i^{\text {th }}$ is usually expressed as the latent model, as shown below:

$$
\begin{aligned}
& Y_{i}^{*}=\beta_{0}+\beta_{1} X_{i 1}+\ldots . .+\beta_{k} X_{i k}+\varepsilon_{i} ; \quad \varepsilon_{i}=\ddot{i} d N\left(0, \sigma^{2}\right) \\
& i=1,2,3 \ldots 116
\end{aligned}
$$

Where;

$Y_{i}^{*}$ is a latent variable, is an index of unobserved variables associated with perceived net benefits of the high tunnels technology. $X_{i k}$ is a vector of farmer's characteristics and $\varepsilon_{i}$ is the error term which is independently distributed random variable with a mean of zero.

A latent variable is unobservable, but a choice made by the individual $i$ can be related to the actual decision taken by the farmer upon observing the discrete choice made as, $Y_{i}$ takes two values, specified as:

$Y_{i} \begin{cases}1, & Y_{i}^{*} \geq 0 \\ 0, & Y_{i}^{*}<0\end{cases}$

$Y_{i}=1$ (if farmer $\mathrm{i}$ adopts) and $\mathrm{Y}_{\mathrm{i}}=\mathrm{o}$ (if farmer $i$ does not adopt). The dependent variable is the adoption decision, assuming the value 1 or 0 . The value 1 indicates a farmer who has adopted the high tunnels with an expectation of positive net benefits whilst o represents those who expect the negative net benefit, non-adopter. Adopters were defined as those farmers that have erected high tunnels and started production under the structure for at least the past six months, while non-adopters were defined as those farmers that do not have the structure and undertook tomato production in an open field.

Thus, the model is expressed as follows in terms of probability formula:

$Y_{i}=1, \quad Y_{i}=0, \quad i=1,2,3 \ldots \ldots 116$

if $\operatorname{Pr}\left[Y_{i}=1 \mid X\right]=\operatorname{Pr}\left[Y^{*} \geq 0 \mid X\right]$

$\operatorname{Pr}(1)=\operatorname{Pr}\left[X_{i}^{\prime} \beta+\varepsilon_{i} \geq 0 \mid X\right]$

$\operatorname{Pr}(1)=\operatorname{Pr}\left[\varepsilon_{i} \geq-X_{i} \beta\right]$

$\operatorname{Pr}(1)=\Phi\left(X_{i}^{\prime} \beta\right) \quad$ given $\quad \sigma=1$

Where $\Phi$ is the cumulative distribution function of standard normal distribution. $\beta$ is the parameters that are estimated by the maximum likelihood method and $X^{\prime}$ is a vector of exogenous variables that explains the adoption of high tunnels.

Therefore, the empirical model was specified as follows:

$$
\begin{aligned}
& \text { HTAdoption }=\beta_{o}+\beta_{1} \text { FarmSiz }+\beta_{2} \text { DstMrkt }+\beta_{3} \text { FarmerOcc }+\beta_{4} \text { NoEduYrs } \\
& +\beta_{5} \text { Male }+\beta_{6} \text { AcCredit }+\beta_{7} \text { AccEXT }+\beta_{8} \text { FamExp }+\beta_{9} \text { Midaged }+\beta_{10} \text { Oldaged }+\varepsilon_{i}
\end{aligned}
$$

Where: HT adoption is High tunnel technology adoption, FarmSiz is farmer size, FarmerOcc is farmer occupation, AcCredit is access to credit, AccEXT is access to extension, FamExp is farmer experience, and Midaged is middle-aged. 
To get a sensible interpretation of coefficients of independent variables related to the adoption of high tunnel technology, the marginal effects were computed. The marginal effect of a variable is the effect of unit change of that variable on the probability of $\operatorname{Pr}\left[Y_{i}=1|X|\right.$, given that other variables are kept constant.

The marginal effect is expressed as

$$
\frac{\partial \operatorname{Pr}\left(Y_{i}=1 \mid X_{i}\right)}{\partial X_{i}}=\frac{\partial E\left(Y_{i} / X_{i}\right)}{\partial X_{i}}=\varphi\left(X_{i}^{\prime} \beta\right) \beta
$$

\section{Results and Discussion}

\section{Respondents' demographic profile}

Approximately $2.5 \%$ and $4.0 \%$ of farmers had adopted the technology in 2010 and 2012, respectively and thereafter following the establishment of the protected farming incubator by LEA in 2011, the number has grown significantly. Male farmers were dominant tomato producers (69\%) in the district. Nonetheless, female farmers had a slight edge in high tunnels tomato production, with almost $15 \%$ of females partaking in the technology compared to $12 \%$ males. The Chi-square statistic shows that there was an association between gender and the type of farming at a $1 \%$ significance level. In addition, the results indicated that the majority (61.2\%) of tomato growers was married and this was true for high tunnels adopters at $20.7 \%$. Marital status and the high tunnels adoption status were found to be correlated at a 10\% significance level. High tunnels adopters were secondary and tertiary graduates at $12.9 \%$ and $13.8 \%$, respectively. A chi-square test revealed that there was a positive association between the high tunnels adoption status and education at a 1\% significance level. Furthermore, it is imperative to note that middle-aged (36-59 years) farmers in the study area at $67.2 \%$ dominated tomato production and the least (11.2\%) were in the age bracket of over 60 years of age.

The study revealed that $54.3 \%$ of farmers were disadvantaged when it comes to access to credit. The majority cited a lack of collateral while others simply feared the risk associated with credit. Moreover, subscription to group membership was very low, with only $39.9 \%$ subscripted. Farmers pointed out that in the past, farmers' associations were plagued by disloyalty and embezzlement of funds, and that led to the groups collapsing. Lack of transparency in activities, cash transactions and poor social cohesion within the association was reiterated as common problems.

Table 1. Summary statistics of adopters and non-adopter of high tunnel technology.

\begin{tabular}{|c|c|c|c|c|c|c|c|}
\hline Variables & Type of farmer & $\mathrm{N}$ & Mean & Std. Dev & Min & Max & P-value \\
\hline \multirow[t]{2}{*}{ Farm size (Ha) } & Adopters & 31 & $5 \cdot 52$ & 1.04 & 3.50 & 8.00 & \multirow[t]{2}{*}{$0.001^{* * *}$} \\
\hline & Non-adopters & 85 & 4.53 & 3.11 & 0.86 & 8.60 & \\
\hline \multirow{2}{*}{$\begin{array}{l}\text { Land allocated to } \\
\text { tomato (Ha) }\end{array}$} & Adopters & 31 & 0.17 & 0.07 & 0.03 & 0.24 & \multirow[t]{2}{*}{$0.000^{* * *}$} \\
\hline & Non-adopters & 85 & 0.34 & 0.17 & 0.06 & 1.00 & \\
\hline \multirow{2}{*}{$\begin{array}{l}\text { Distance to the } \\
\text { market }(\mathrm{km})\end{array}$} & Adopters & 30 & $43 \cdot 37$ & 20.02 & 3.00 & 58.00 & \multirow[t]{2}{*}{0.395} \\
\hline & Non-adopters & 72 & 45.62 & 13.72 & 22.00 & 70.00 & \\
\hline \multirow{4}{*}{$\begin{array}{l}\text { Age of head of } \\
\text { household } \\
\text { Farmer Experience }\end{array}$} & Adopters & 31 & 41.71 & $7 \cdot 36$ & 34.00 & 60.00 & \multirow[t]{2}{*}{$0.035^{* *}$} \\
\hline & Non-adopters & 85 & 46.87 & 12.69 & 22.00 & 68.00 & \\
\hline & Adopters & 31 & 4.03 & 1.87 & 1.00 & 9.00 & \multirow[t]{2}{*}{$0.003^{* * *}$} \\
\hline & Non-adopters & 85 & 6.58 & 4.46 & 0.00 & 16.00 & \\
\hline \multirow{5}{*}{$\begin{array}{l}\text { No of Extension } \\
\text { visits } \\
\text { Annual farm } \\
\text { Income } \\
\text { (BWPula) }\end{array}$} & Adopters & 31 & 4.03 & 3.01 & 0.00 & 8.00 & \multirow[t]{2}{*}{0.247} \\
\hline & Non-adopters & 84 & 3.25 & 3.27 & 0.00 & 10.00 & \\
\hline & Adopters & 31 & 218 & 80850.73 & 75114 & 358246 & $0.000^{* * *}$ \\
\hline & & & 506.19 & & & 473306 & \\
\hline & Non-adopters & 85 & $\begin{array}{c}119 \\
266.48\end{array}$ & 98618.83 & 14500 & & \\
\hline
\end{tabular}

Source: Survey result, 2017 asterisks*, ${ }^{* *}$ and ${ }^{* * *}$ significant level at 10,5 and $1 \%$, respectively

High tunnels adopters had relatively larger plots than non-adopters, with a mean farm size of 5.52 ha for high tunnels adopters but the mean area of land allocated to tomato production by high tunnel adopters was less than for open-field farmers. In that regard, the findings show that open field uses more land for tomato production than the high tunnel technology. Annual farm income and farmer experience were also statistically different at $1 \%$, with average farm income for high tunnels adopters approximately two times that of non-adopters.

\section{Constraints that hinder adoption of high tunnels}

Farmers reiterated prohibitive cost of the high tunnel, lack of technical knowledge, lack of access to credit and market inadequacy as key constraints that hinder high technology adoption. 
The majority of the farmers $(53.8 \%)$ indicated that the cost of high tunnels was one of the major constraints (Fig. 2). High tunnel technology inclusive of complementary inputs requires significant (if not huge) start-up capital that making the technology unaffordable especially for smallholders. An average price for a single tunnel was BWP 66508.03 (U\$D 6451.28), with the least cost of BWP 50 ooo (U\$D 4850). The cost is further exacerbated by external sourcing of the technology mainly from South Africa. These make the investment in the technology trick especially for medium and small scale farmers who are financially challenged. Majority of the farmers cannot meet the collateral requirement by financial institutions for credit qualification. Cremades et al. (2015) emphasized that appropriate financial assistance is key in the adoption of modern technology by farmers.

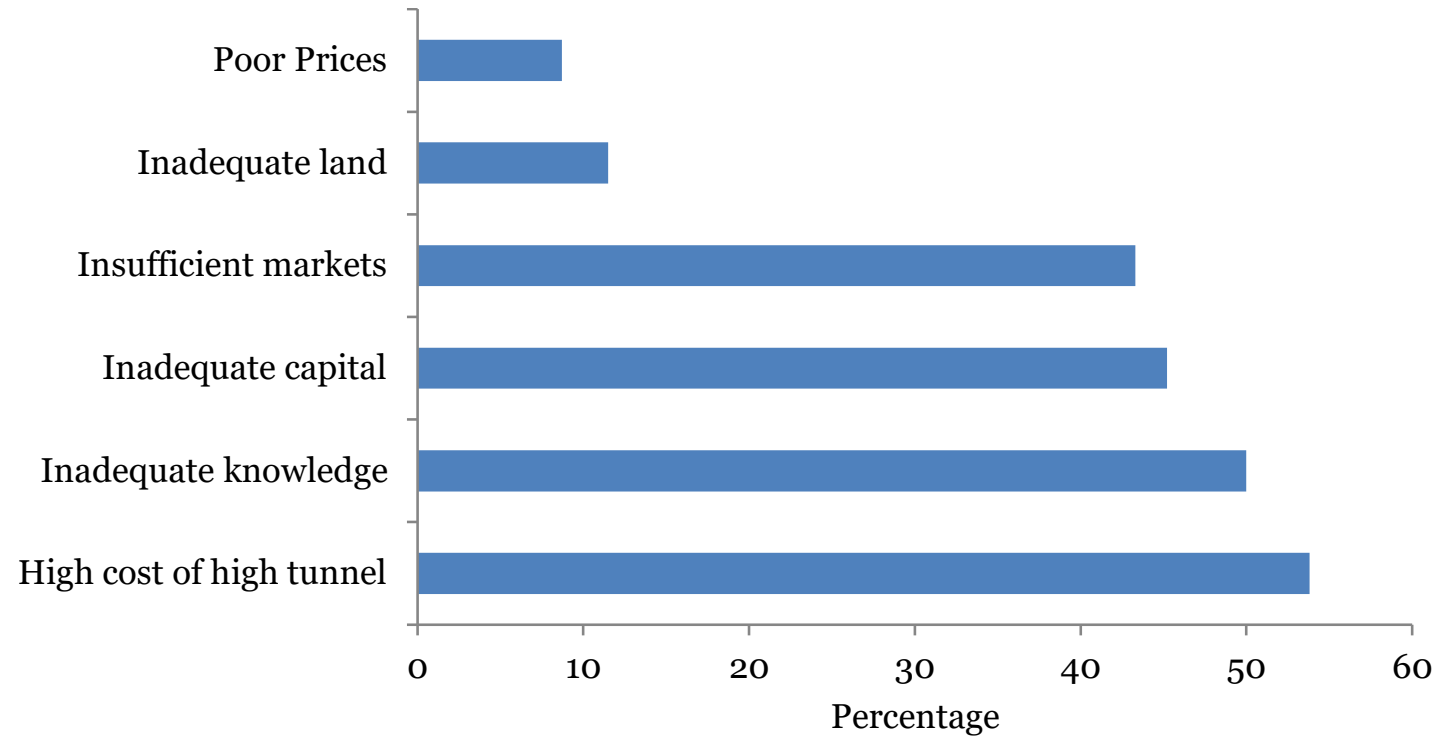

Fig. 2. Factors that hinder the adoption of high tunnel.

Note: Frequency totals are more than 100\% due to multiple responses

Yet the majority (89.66\%) of the farmers indicated that they were aware of the production system, half of the farmer's reiterated lack of knowledge especially the management of crops under high tunnels production system. The sampled farmers expressed challenges of disease and pests control such as fungus and nematodes. Surprisingly tunnels adopters also reiterated the same, especially the know-how on the management of tomato under tunnels, hence during the outbreak of leaf miner (Tuta absoluta), the farmers were also hit hard. Bhatnagar (2014) revealed that protected farming in India remains accessible to a few farmers although subsidies may cover 50 to $90 \%$ of initial investment partly due to lack of information. This emphasized the pivotal role of training, teaching, and establishment of technology informationsharing platforms to expedite technology adoption.

Lack of a well-developed value chain or market for tomatoes makes farmers sceptic to invest in such a relatively costly technology, with no assurance or certainty on produce absorption by the market. Currently, there are no tomato valueadding industries in the country. The newly established processing plant demanded only 32 tonnes per month of tomatoes as of 2017, which was far less than the local production and only one Botswana horticulture market outlet was operational. The same problem was revealed by Farida and Fariya (2014), in Ghana as a major marketing constraint for tomato producers. Farmers also expressed their dissatisfaction regarding high volumes of fresh tomatoes from South Africa even when the local produce was in abundance by big retails and chain stores operating in the country.

Farmers in the district also attributed low adoption of the technology to lack of collateral and decried stringent credit terms and conditions at financial institutions. Small scale farmers therefore largely depended on their meagre resources which in most cases are not adequate to purchase such technology. Farmers were less impressed by financial assistance offered by the government especially that the sub-sector is considered to be a potential economic diversifier. Other factors indicated by farmers include inadequate land and poor prices.

\section{Determinants of high tunnel technology adoption}

The binary probit model was estimated with robust standard errors to correct for heteroscedasticity and other misspecification 
problems since the data used in estimation were from a cross-sectional survey. As a rule of thumb, values of variance inflation factor (VIF) of greater than 10 are regarded as a signal for the existence of a severe multicollinearity problem in regression models (Gujarati, 2004). The model had a mean VIF of 5.75 and no correlations were noticeable from the correlation matrix, hence concluding that multicollinearity was not a problem.

A glance at Table 2 attested the model significance at $1 \%$ level, with the log-likelihood function Chi-squared value of 58.68. This meant that the model adequately explained the relationships between the dependent and independent variables. Consequently, the hypothesis that the adoption of high tunnels is not influenced by farm size, head of household's education, occupation, farmer's experience, and access to extension, access to credit, age gender and distance to the market was rejected at o.o1significance level. It implies that all explanatory variables included in the model jointly influence the adoption of high tunnels technology in the study area.

Another indicator of the model's overall fit was the estimated value of McFadden pseudo- $\mathrm{R}^{2}$ of 0.621, which considering the cross-sectional nature of the data indicated that the model had fair predictive power.

As expected, the regression results (Table 2) showed that farm size, years of education, and access to extension had a positive and significant relationship with the probability of adopting the high tunnel technology. However, the farmer's experience had a negative relationship with the probability of high tunnel adoption. The results show that an additional increase in farming experience was estimated to decrease the probability of adopting high tunnel technology by 2.3\% ( $\mathrm{P}>0.05)$, holding other things constant. Farmers who adopted high tunnels were less experienced in comparison to non-adopters. This might be derived from the fact that as a farmer gains experience in a given production system, experimenting with the system is common, leading to modify it to suit them, hence more experienced farmers are more comfortable and resist switching to innovations. Experienced farmers often receive any radical innovation with scepticism, as they are often wary of a system or technology that is different from the one they are familiar with. This means that the risk aversion factors increase with increase inexperience. The same was revealed by Mwangi (2012) who noted that more experienced farmers were negatively associated with the adoption of greenhouse tomato farming.

Medium size farms (5-10 ha) allow for the installation of such big structures and still have enough space for other crops, this is in assent with the descriptive results, as high tunnels adopters had larger farms compared to their open field counterparts. Usually, such technology comes with complementary inputs such as a fertigation system, which allows for efficient application of fertilizer and more land is required to accommodate the whole technology. The findings are in line with various authors including Asfaw et al. (2016), Abara and Singh (1993) and Akudugu et al. (2012). This presents a serious challenge for the adoption of modern agricultural production technologies in the study area because the majority of farm households in the district operate on a small scale with average farm sizes hardly exceeding five hectares.

Table 2. Factors influencing the adoption of high tunnel.

\begin{tabular}{|l|l|l|l|l|l|}
\hline $\begin{array}{l}\text { Probit regression } \\
\text { Variables }\end{array}$ & Coef. & Std. Err. & dy/dx & Std. Err. & P $>$ Z \\
\hline High Tunnels Adopters & & & & & \\
\hline Farm size & 0.271 & 0.121 & $0.045^{* *}$ & 0.020 & 0.026 \\
\hline Education (No of Years) & 0.175 & 0.064 & $0.029^{*}$ & 0.016 & 0.061 \\
\hline Occupation (Farming=1) & 0.018 & 0.750 & 0.003 & 0.127 & 0.981 \\
\hline Farm Experience & -0.140 & 0.080 & $-0.023^{* *}$ & 0.011 & 0.034 \\
\hline Extension service (Yes=1) & 1.473 & 0.417 & $0.368^{* *}$ & 0.151 & 0.015 \\
\hline Access to Credit (Yes=1) & 0.617 & 0.545 & 0.107 & 0.074 & 0.145 \\
\hline Middle Aged (36-59) & 1.066 & 0.422 & 0.144 & 0.091 & 0.112 \\
\hline Old Aged (>60) & 1.184 & 0.857 & 0.320 & 0.262 & 0.222 \\
\hline Log_Distance to Markets & -0.301 & 0.322 & -0.050 & 0.051 & 0.327 \\
\hline Gender (Male=1) & -0.705 & 0.444 & -0.140 & 0.099 & 0.158 \\
\hline Constant & -3.414 & 1.334 & & & \\
\hline No of Obs (n) & 116 & & & & \\
\hline Wald chi ${ }^{2}$ (10) & 58.68 & & & & \\
\hline Prob chi & & & & & \\
\hline Pseudo R & & & & & \\
\hline Log pseudolikelihood & -26.102 & & & & \\
\hline
\end{tabular}

Source: Survey result, 2017 asterisks* and ${ }^{* *}$ significant level at 10 and $5 \%$, respectively. 
Years of education and farm size are estimated to increase the probability of adopting high tunnels by $2.9 \%$, and $4.5 \%$, respectively, holding other things constant. It is worth to note that high education is assumed to relax the complexity perception of new technologies and as argued by Caswell et al. (2001) and Lapar and Ehui (2004), education creates a favourable mental attitude for the acceptance of new practices, especially information-intensive and managementintensive practices. Therefore, farmers with more years of education can comprehend better such production technology and they are willing to invest in sustainable production systems than those with few years of education. The result is consistent with findings by Cremades et al. (2015), that farmers with a higher education level are more likely to adopt modern new technologies faster.

Access to the extension has been labelled as an influential factor in various studies of new technology adoption (Cremades et al., 2015 Kassa et al., 2014; Akudugu et al., 2012). As hypothesized, the study results affirmed that the probability that farmers adopt high tunnel technology is estimated to increase by $36.8 \%$ $(\mathrm{P}>0.05)$ ceteris paribus, when extension services are accessible to the farmers. The provision of extension services makes a valuable contribution by disseminating information about the beneficial aspects of the technology and can also complement low levels of education in the overall decision to adopt certain technologies. Access to information reduces the uncertainty about a technology's performance therefore effective extension services assist to change farmers' assessment over time of the new technology thereby facilitating its adoption.

\section{Conclusion and Recommendations}

Overall, these analyses indicate that the adoption of high tunnels in the study area is not solely conditioned by the cost of the structure; there are several interplaying socio-economic and institutional factors. In that regard, understanding and appreciating these linkages can enable effective intervention and subsequently speeding the technology adoption in the district and the country at large. Moreover, addressing the aforementioned constraints will improve the adoption rate of the technology and therefore, resulting in a positive impact on the tomato industry in the study area and Botswana at large.

Given major findings and the conclusion, the study suggests that strengthening extension service and re-engineering of the current extension system is necessary for improving the adoption rate of the technology. Intensified high tunnels technology information dissemination through short courses, workshops, and in-field training in the district and country would be ideal.

The study further suggests that tunnel designers should consider constructing the structure using local materials to cut down costs on the technology, for instance using treated Eucalyptus poles. This has been a success story in Kenya and Nigeria, using a bamboo tree. In addition, both the government and the private sector should establish value-adding industries to help create appealing and reliable markets for farmers and in turn, can result in the adoption of such production enhancing technologies like high tunnels.

A more intensive study using panel data is suggested because adoption is a dynamic process that needs investigation over time, so a crosssectional study might not be sufficient.

\section{References}

Abara, I.O.C. and Singh, S. 1993. Ethics and biases in technology adoption: The small farm argument. Tech. Fore. Soc. Change. 43: 289-300. https://doi.org/10.1016/00401625(93)90057-E

Aikens, M.T., Havens, A.E. and Flinn, W.L. 1975. The adoption of innovations: the neglected role of institutional constraints. Mimeograph. Department of Rural Sociology, The Ohio State University, Columbus, Ohio, USA. pp. 279-296.

Akudugu, M., Guo, E. and Dadzie, S. 2012. Adoption of modern agricultural production technologies by farm households in Ghana: What factors influence their decisions? $J$. Biol. Agric. Healthcare. 2(3): 1-13.

Al-Shadiadeh, A.N., Al-Mohammady, F.M. and Abu-Zahrah, T.R. 2012. Factors influencing adoption of protected tomato farming practices among farmers in Jordan Valley. J.World Appl. Sci. 17(5): 572-578.

Apata, T.G. 2011. Factors influencing the perception and choice of adaptation measures to climate change among farmers in Nigeria. Evidence from farm households in Southwest Nigeria. Environ. Econ. 2(4): 74-83.

Asfaw, S., Federica, D.B. and Lipper, L. 2016. Agricultural Technology Adoption under Climate Change in the Sahel: Microevidence from Niger. J. African Econ. 25(5): 637-669. https://doi.org/10.1093/jae/ejwoo5

Aubert, M., Codron, J., Rousset, S. and Yercan, M. 2013. The adoption of IPM practices by small scale producers: the case of greenhouse tomato growers in Turkey. In: $140^{\text {th }}$ EAAE seminar, Theories and Empirical application on policy and government of Agric-food chains, Perugia, Italy. 27p. 
Baliyan, S.P. 2014. Improving sustainable vegetable production and income through net shading: A case study of Botswana. $J$. Agric. Sust. 5(1): 70-103.

Baliyan, S.P. and Rao, M.S. 2013. Evaluation of tomato varieties for pest and disease adaptation and productivity in Botswana. Int. J. Agril. Food Res. 2(3): 20-29. https://doi.org/10.24102/ijafr.v2i3.297

Bhatnagar, P.R. 2014. Strategies for protected cultivation for small and marginal farmers in India. In: Agricculture: Towards a new paradigm of sustainability. New Delhi, India: Excellent publishing house. 158p.

Carey, E.C., Jett, L., Lamont, Jr.W.J., Nennich, T.T., Orzolek, M.D. and Williams, K.A. 2009. Horticultural crop production in High Tunnels in the United States: A Snapshot. HortTech. 19(1): 25-36. https://doi.org/10.21273/HORTSCI.19.1.37

Caswell, M., Fuglie, K., Ingram, C., Jans, S. and. Kascak, C. 2001. Adoption of Agricultural Production Practices: Lessons Learned from the U.S. Department of Agriculture Area Studies Project. Agril. Econ. 792: 116.

Central Statistics Office. 2011. Botswana Housing Statistics. Government Printers, Gaborone, Botswana. 88p.

Cremades, R., Wang, J. and Morris, J. 2015. Policies, economic incentives and the adoption of modern irrigation technology in China. Earth Syst. Dynam. 6: 399-410. https://doi.org/10.5194/esd-6-399-2015

D’Antoni, J.M., Mishra, A.K. and Joo, H. 2012. Farmers' perception of precision technology: The case of autosteer adoption by cotton farmers. Comp. Elect. Agric. 87: 121-128. https://doi.org/10.1016/j.compag.2012.05.017

DAFF. 2017. A Profile of the South African tomato market value chain. Department of Agriculture, Forestry and Fisheries, South Africa. 42p.

[https://www.nda.agric.za/doaDev/sideMen u/Marketing/Annual\%20Publications/Com modity\%20Profiles/field\%20crops/Tomato \%20Market\%2oValue\%2oChain\%20Profile $\% 202017 . p d f]$

Department of Meteorological Services. 2017. Botswana Agrometeorological Monthly Bulletin. Agromet. Bull. 2(4): 6.

Disele, S. 2018. Tomato production below demand. DailyNews.

[http://www.dailynews.gov.bw/newsdetails.php?nid=45868]

Drost, D. and Wytsalucy, R. 2014. High Tunnel Green Bean Production. All Current Publications. Paper 681.

https://doi.org/10.1007/978-3-642-417146_81093

FAO. 2013. FAOSTAT. Tomatoes production quantity. [www.fao.org/faostat/en/\#data/OA.].

Farida, A. and Fariya, A. 2014. Analysis of Production and Marketing Constraints of Tomato among Rural Farmers in Talensi Nabdam District of Upper East Region of
Ghana. IJASRT in EESs. 4(1): 57-60. https://ssrn.com/abstract $=2568171$

Field, C.B., Barros, V.R., Dokken, D.J., Mach, K.J., Mastrandrea, M.D., Bilir, T.E., Chatterjee, M., Ebi, K.L., Estrada, Y.O., Genova, R.C. and Girma, B. 2014. International Panel on Climate Change. Impacts, Adaptation, and Vulnerability. Part A: Global and Sectoral Aspects. Contribution of Working Group No. 2. Intergovernmental Panel on Climate Change. 1142p.

Gujarati, D.N. 2004. Basic Econometrics. Fourth Edition. New York: McGraw-Hill. 1024p.

Howley, P. and Heanue, K. 2012. Factors affecting farmers' adoption of agricultural innovations: A panel data analysis of the use of artificial insemination among dairy farmers in Ireland. J. Agric. Sci. 4(6): 171179. https://doi.org/10.5539/jas.v4n6p171

Hosmer, D. W. and Lemeshow, S. 2000. Applied Logistic Regression. Second Edition John Wiley and Sons, Inc. 383p. https://doi.org/10.1002/0471722146

Ibrahim, M., Florkowski, W. and Kolavalli, S. 2012. The determinants of farmer adoption of improved peanut varieties and their impact on farm income: evidence from Northern Ghana. In: Agricultural and Applied Economics Association Annual Meeting Seattle, 12-14 August 2012. pp. 116.

Kassa, B., Kassa, B. and Aregawi, K. 2014. Adoption and Impact of Agricultural Technologies on farm income: Evidence from Southern Tigray, Northern Ethiopia. Int. J. Food Agril. Econ. 2(4): 91-106.

Labaran, M. 2015. Assessing the factors influencing the adoption of biopesticides in vegetable production in the Ashanti Region of Ghana. MSc Thesis, Kwame Nkrumah University, Ghana. 153p.

Lapar, M.L.A. and Ehui, S.K. 2004. Factors affecting the adoption of dual-purpose forages in the Philippine uplands. Agric. Syst. 81: 95-114.

https://doi.org/10.1016/j.agsy.2003.09.003

LEA. 2015. Annual Report 2014-15. Local Enterprise Authority, Government Printers, Gaborone, Botswana. 84p.

Madisa, M.E. 2012. Analysis of horticultural production trends in Botswana. J. Plant Stud. 1(1): 1-11.

https://doi.org/10.5539/jps.v1n1p25

Manda, J., Alene, A.D., Gardebroek, C., Kassie, M. and Tembo, G. 2016. Adoption and impacts of sustainable agricultural practices on maize yields and incomes: evidence from rural Zambia. J. Agric. Econ. 67: 130-153. https://doi.org/10.1111/1477-9552.12127

Murage, A.W., Pittchar, J.O., Midega, C.A.O., Onyango, C.O. and Khan, Z.R. 2015. Genderspecific perceptions and adoption of the climate-smart push e pull technology in eastern Africa. Crop Prot. 76: 83-91. https://doi.org/10.1016/j.cropro.2015.06.014 
Mwangi, W.J. 2012. Comparative analysis of greenhouse versus open-field small-scale tomato production in the Nakuru-north district. MSc Thesis, Egerton University, Kenya. 88p.

North East District Development Plan 6. 2004. Ministry of Local Government. Gaborone, Botswana. 193p.

O’Connell, S., Rivard, C., Peet, M.M., Harlow, C. and Louws, F. 2012. High tunnel and field production of organic heirloom tomatoes: Yield, fruit quality, disease, and microclimate. HortSci. 47(9): 1283-1290. https://doi.org/10.21273/HORTSCI.47.9.1283

Prager, K. and Posthumus, H. 2010. Socioeconomic factors influencing farmers' adoption of soil conservation practices in Europe. In: Napier, T.L. (Ed.) Human Dimensions of Soil and Water Conservation, Nova Science Publishers. pp. 203-223.

Ramaeker, L., Micheni, A., Mbogo, P., Vanderleyden, J. and Maertens, M. 2013. Adoption of climbing beans in the central highlands of Kenya: An empirical analysis of farmers' adoption decisions. African $J$. Agril. Res. 8(1): 1 - 19.

Ranganai, R.T., Moidaki, M. and King, J.G. 2015. Magnetic Susceptibility of soils from Eastern Botswana: A reconnaissance survey and potential applications. J. Geograp. Geol. 7(4): 9779-9787.

https://doi.org/10.5539/jgg.v7n4p45
Rogers, E. 1962. Diffusion of Innovations $\left(3^{\text {rd }}\right.$ Ed.) Free Press, Division of Macmillian Publishing Co., New York. 236p.

Roling, M. 1988. Extension science: Information system in agricultural development. Cambridge University Press: Cambridge. 233p.

Statistics Botswana. 2016a. Agricultural census starts brief 2015. Statistics Botswana, Gaborone, Botswana. 14p.

Statistics Botswana. 2016b. Vegetable imports 2014-2016 Report. Statistics Botswana. Gaborone, Botswana. 1op.

United Nations. 2005. Designing Household Survey Samples: Practical Guidelines. United Nations, New York. 255p.

Waterer, D. 2003. Yields and economics of high tunnels for production of warm-season vegetable crops. HortTech. 13: 339-343. https://doi.org/10.21273/HORTTECH.13.2.0339

Wells, O.S. and Loy, J. B. 1993. Row covers and high tunnels enhance crop production in the North Eastern United States. HortTech. 3: 92-95. https://doi.org/10.21273/HORTTECH.3.1.92

World Economic Forum. 2016. Global Risks. Geneva: World economic forum. http://www.weforum.org/repo6.3.2rts/glob al-risks-report-2015 